\title{
MRI findings of prolonged post-traumatic sternal pain
}

\author{
Alexandra Grosse • Claudia Grosse • Lynne Steinbach • \\ Suzanne Anderson
}

Received: 29 April 2006 /Revised: 1 October 2006 / Accepted: 10 January 2007 / Published online: 6 March 2007

(C) ISS 2007

\begin{abstract}
Objective The objective of this study was to characterize the different causes of prolonged sternal pain following thoracic trauma with involvement of the sternum and to define criteria for sternal nonunion diagnosis using MRI. Design and patients Five patients with abnormalities of the sternum were evaluated for prolonged sternal pain following thoracic trauma using MRI. MR images were evaluated by two radiologists in consensus. The patients were selected from the radiology database, which included 8 patients with post-traumatic prolonged sternal pain.

Results Two patients $(n=2)$ revealed a sternal nonunion after sternal fracture. One patient had a sternal fracture with delayed union and minor displacement of the sternal halves. Abnormal signal intensity alterations adjacent to and within the manubrio-sternal joint were evident in 2 patients and considered due to trauma-related changes in the manubriosternal joint. The 3 patients who were not included in the study had no abnormalities of the sternum: 1 of them proved to have a well-healed sternal fracture and nonunion of a rib fracture, 1 had subtle Tietze's syndrome, and 1 patient revealed no pathological findings on imaging.

Conclusion Various factors may be responsible for prolonged sternal pain following thoracic trauma, and these can be viewed with MRI. In cases of sternal nonunion there was common fluid-like signal in the fracture interspace
\end{abstract}

A. Grosse $(\bowtie) \cdot$ C. Grosse $\cdot$ S. Anderson

Department of Diagnostic, Pediatric and Interventional Radiology,

University Hospital of Berne,

Inselspital, Freiburg Strasse,

3010 Berne, Switzerland

e-mail: alexandragrosse@gmx.at

L. Steinbach

Department of Radiology, University of California San Francisco,

San Francisco, CA 94143-0628, USA between the bony edges, and the bone marrow adjacent to the nonunion showed altered signal intensity. MRI identified sternal nonunion and other trauma-related abnormalities of the sternum following chest trauma.

Keywords Sternum · Chest pain · Trauma · Nonunion · Magnetic resonance imaging

\section{Introduction}

Prolonged post-traumatic sternal pain in the absence of infection may be caused by various conditions including sternal nonunion or delayed union following sternal fracture and post-traumatic changes in the manubrio-sternal joint [1-6]. To date, no studies have been reported describing the MRI findings of these rare post-traumatic disorders and evaluating the usefulness of MRI in this setting.

In this study we present the cases of 5 patients with prolonged sternal pain following thoracic trauma with sternal injury in the absence of infection. We report on the characteristic MRI findings of sternal nonunion in our collective and present the imaging features of other posttraumatic sternal disorders responsible for prolonged posttraumatic sternal pain.

\section{Materials and methods}

Five patients ( 1 female and 4 males) presented to our hospital between September 2000 and June 2004 with prolonged post-traumatic sternal pain. They ranged in age from 30 to 66 years (mean, 52 years \pm 11.9 ). They presented with discomfort and persistent pain following trauma with involvement of the sternum in the absence of local or 
disseminated infection. The pain worsened on activity and movement. The patient list was generated from the database of the radiology department compiled from retrospective chart review of all patients who had been referred from the thoracic department with prolonged sternal pain following thoracic trauma and with a suspected sternum-related cause of the pain. A total of 8 patients with prolonged posttraumatic sternal pain were analyzed. Two patients underwent CT: 1 of them revealed a well-healed sternal fracture and a nonunion of a rib fracture; the other patient underwent further MRI examination and had a final diagnosis of subtle Tietze's syndrome, but no abnormality of the sternum. One patient with a history of sternal contusion after a car accident proved to have no pathological findings on CT and MRI. These 3 patients had no abnormalities of the sternum and were therefore not included in this study. The remaining 5 patients proved to have abnormalities of the sternum that were regarded as the cause of their prolonged post-traumatic sternal pain. These 5 patients were included in this study.

One of the 5 patients with abnormalities of the sternum presented with prolonged pain after falling from a ladder with the sternum against a wood block. CT imaging at the time of trauma had demonstrated lung contusions, rib fractures, and a sternal fracture in the mid third of the sternum, which had been treated conservatively. One patient had suffered sternal injury due to a fist blow against the sternum, 2 patients had been involved in car accidents, and 1 patient had had a parachute accident with a fall from a great height.
Physical examination on hospital admission revealed a palpable step in the anterior chest wall in 1 patient and sternal instability in another patient. The female patient and the parachuter complained about pain localized especially to the manubrio-sternal joint on clinical examination. Two of the five patients were severely limited in their routine activities due to severe sternal pain.

Magnetic resonance images of the sternum were available for retrospective review in all 5 patients. Correlation of the imaging findings with the patient's history and symptoms at physical examination was performed. The MR images of the 5 patients were assessed by two musculoskeletal radiologists, and MRI findings were correlated with the surgical findings in 2 patients. The MR images were performed on a 1.5-Tesla Siemens system (Sonata; Siemens, Erlangen, Germany). T1-weighted images were acquired in the coronal and axial planes with a repetition time (ms)/echo time (ms) of 516-585/12-17, a matrix size of $512 \times 512$, FOV 24 (axial) and 30 (coronal), with $3 \mathrm{~mm}$ (coronal) and $5 \mathrm{~mm}$ (axial) slice thickness and an interslice gap of $1 \mathrm{~mm}$. STIR sequences were acquired in the axial plane using a repetition time $(\mathrm{ms}) /$ echo time $(\mathrm{ms})$ of 4,100-4,842/17-76, a matrix size of $256 \times 256$, FOV 30 and slice thickness of $3 \mathrm{~mm}$ with an interslice gap of $1 \mathrm{~mm}$. Fat-saturated T1-weighted images following contrast enhancement were acquired in the axial, coronal, and sagittal planes with a repetition time (ms)/echo time (ms) of 476-900/ $12-17$, a matrix size of $512 \times 512$, FOV $24-30$, and a slice thickness of $3 \mathrm{~mm}$ (coronal and sagittal) and $5 \mathrm{~mm}$ (axial). MRI was performed in the prone position to restrict thoracic

Table 1 Clinical presentations and imaging findings

\begin{tabular}{|c|c|c|c|c|c|c|}
\hline $\begin{array}{l}\text { Patient } \\
\text { sex/age } \\
\text { (years) }\end{array}$ & History & Symptom duration & $\begin{array}{l}\text { Time interval } \\
\text { between trauma } \\
\text { and MRI }\end{array}$ & MRI & $\mathrm{CT}$ & Surgery \\
\hline $\begin{array}{l}\text { Case } 1 \\
\text { male/56 }\end{array}$ & $\begin{array}{l}\text { Fall from height } \\
\text { against a wood } \\
\text { block }\end{array}$ & 7 months & 6 months & $\begin{array}{l}\text { Sternal gap, adjacent bone marrow edema, } \\
\text { fluid-like signal in the interspace- - nonunion }\end{array}$ & N/A & Yes \\
\hline $\begin{array}{l}\text { Case } 2, \\
\text { male/66 }\end{array}$ & $\begin{array}{l}\text { Fist blow } \\
\text { against the } \\
\text { sternum }\end{array}$ & $\begin{array}{l}9 \text { months } \\
\text { (patient rejected } \\
\text { surgery and was lost } \\
\text { to follow-up) }\end{array}$ & $\begin{array}{l}1 \text { month } \\
(1 \text { st MRI) } \\
9 \text { months } \\
(2 \text { nd MRI) }\end{array}$ & $\begin{array}{l}\text { 1st MRI: sternal fracture with bone marrow } \\
\text { edema } \\
\text { 2nd MRI: sternal dehiscence, decreased bone } \\
\text { marrow edema, fluid collection in the } \\
\text { interspace - nonunion }\end{array}$ & $\begin{array}{l}\text { Sternal } \\
\text { disruption, } \\
\text { sclerosed } \\
\text { edges }\end{array}$ & No \\
\hline $\begin{array}{l}\text { Case } 3 \text {, } \\
\text { male/56 }\end{array}$ & Car accident & 6 months & 5 months & $\begin{array}{l}\text { Fracture with minor displacement, } \downarrow \text { signal on } \\
\mathrm{T} 1 \mathrm{~W} \text {, } \uparrow \text { signal on STIR, edematous callus- } \\
\text { delayed union }\end{array}$ & N/A & Yes \\
\hline $\begin{array}{l}\text { Case } 4 \text {, } \\
\text { female/ } \\
30\end{array}$ & Car accident & $\begin{array}{l}3 \text { years and } 8 \\
\text { months (then lost to } \\
\text { follow-up) }\end{array}$ & 9 months & $\begin{array}{l}\text { Bone marrow edema adjacent to the manubrio- } \\
\text { sternal joint, fluid in the joint - manubrio- } \\
\text { sternal osteosynchondrosis }\end{array}$ & N/A & No \\
\hline $\begin{array}{l}\text { Case } 5 \\
\text { male/52 }\end{array}$ & $\begin{array}{r}\text { Parachute } \\
\text { accident }\end{array}$ & $\begin{array}{l}1 \text { year and } 11 \\
\text { months (then lost to } \\
\text { follow-up) }\end{array}$ & 20 months & $\begin{array}{l}\text { Bone marrow edema adjacent to the manubrio- } \\
\text { sternal joint, fluid in the joint- manubrio- } \\
\text { sternal osteosynchondrosis }\end{array}$ & N/A & No \\
\hline
\end{tabular}

$N / A$ not available, STIR short tau inversion recovery, $T 1 W$ T1-weighted image 
movement during respiration compared with the supine position, with the field including the sternoclavicular joints and the manubrio-sternal and costo-sternal joints. CT examination with reconstructions was performed in 1 patient.

\section{Results}

The time interval between initial trauma and MRI evaluation ranged from 5 months to 20 months (mean 9.8 months \pm 5.3 ). The patients underwent imaging 5, 6, 9, 9, and 20 months after trauma. Two patients underwent surgery for sternal repair including exposition of the sternum, debridement of the overlying fibrous tissues and sternal edges, and reclosure using dedicated fixation material. The patients remained symptom-free after surgery and experienced no recurrence of their symptoms in the postoperative period and throughout the follow-up. One patient with sternal nonunion refused surgery and requested conservative treatment. The 2 remaining patients were treated conservatively with a follow-up over a 44-month and a 23 -month period, respectively. The patient details are summarized in Table 1.

\section{Imaging}

A total of $6 \mathrm{MR}$ images were performed (1 patient had a follow-up MRI). MRI demonstrated the presence of sternal nonunion in 2 patients, confirmed with surgery in 1 of them. The nonunions were located between the fourth and fifth ribs (Fig. 1) and at the level of the third anterior rib (Fig. 2), and in both cases the nonunion was horizontal. The bony edges of the proximal and distal fracture ends were slightly irregular in case 1 (hypertrophic nonunion), and a fluid-like signal was seen in the nonunion interspace. In the second case the fracture ends were smoothly marginated (atrophic nonunion), and there was a slight ventro-dorsal off-set between the bony edges. CT examination was available in 1 patient with sternal nonunion showing a disruption of the sternum and sclerosis of the sternal edges. Sternal fracture with delayed union and minor displacement of the fracture ends was seen in 1 patient, and this was intraoperatively confirmed (Fig. 3). A transverse line measuring $5 \mathrm{~mm}$ in width was seen in the mid third of the sternal body, the distal sternal part was anteriorly dislocated by $4 \mathrm{~mm}$. No disruption of the sternal continuity and no bone marrow signal alterations of the proximal and distal sternal parts were evident. The patient's pain was primarily centered around this region, and the T1-weighted hypointense and STIR hyperintense focal area was thought to represent edematous callus formation, completely filling the initial fracture interspace. As an additional finding, bone marrow signal alterations were seen adjacent to the fluid-filled manubriosternal joint. This region was less painful on clinical examination, and the finding was thought to be incidental. The patient was operated on clinical grounds because of his

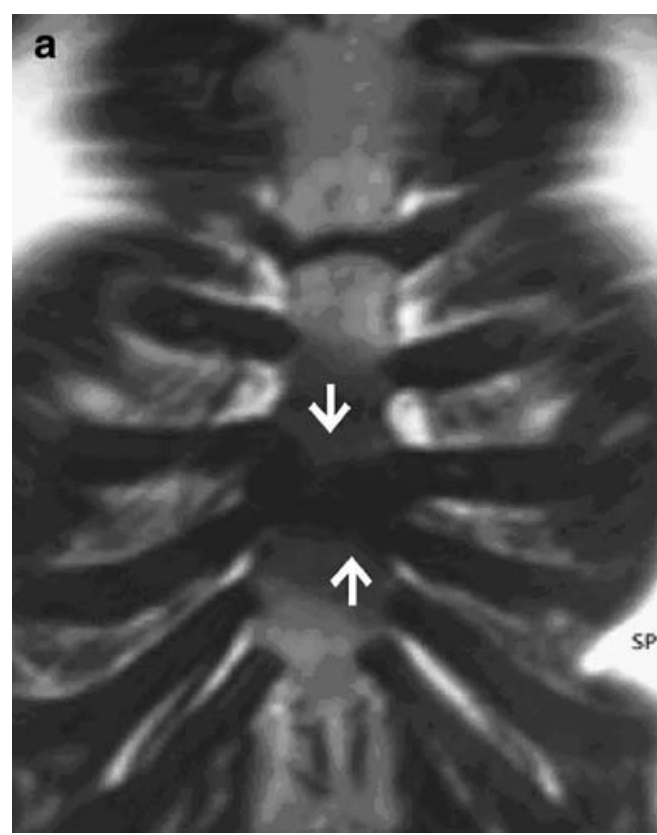

Fig. 1 Fifty-six-year-old man with sternal nonunion after sternal fracture. a Coronal (TR/TE; 559/12) and b sagittal T1-weighted (TR/ TE; 516/12) images show altered bone marrow signal intensity on either side of the nonunion (arrows). c Corresponding coronal STIR image (TR/TE; 4,615/76) shows a transverse disruption in the midst of the sternum between the fourth and fifth ribs with slightly irregular
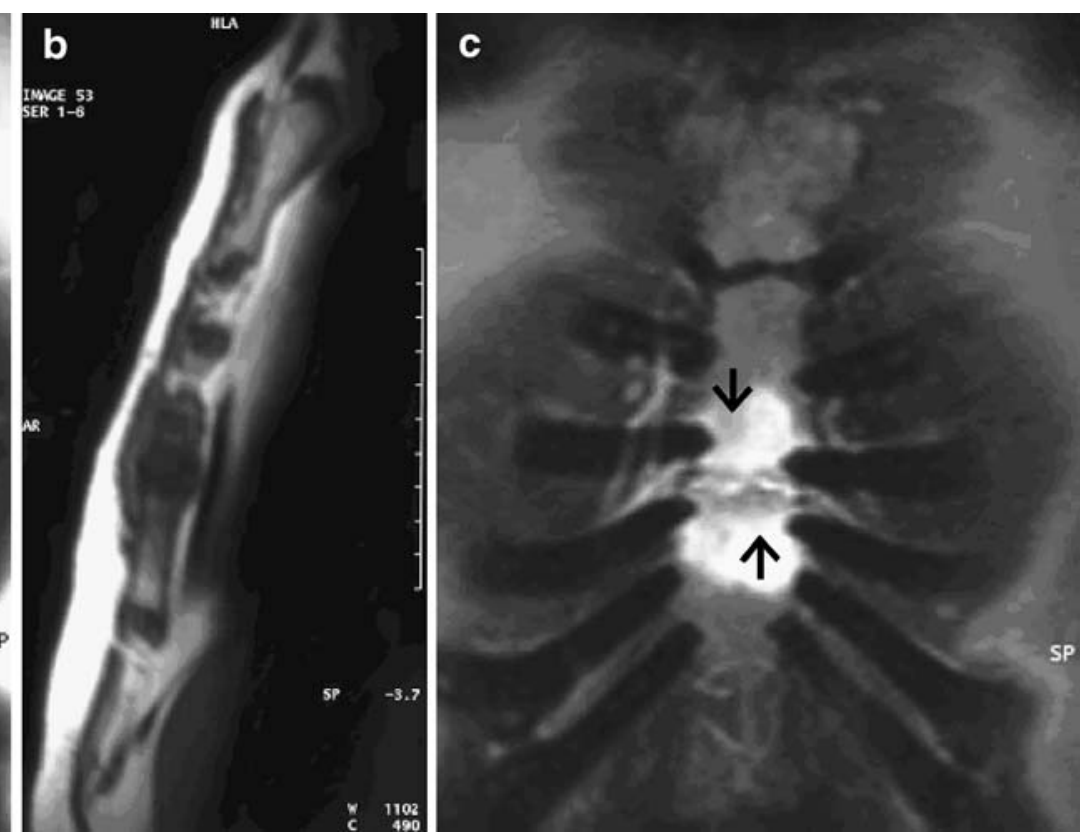

bony edges at the level of nonunion (arrows). Note the fluid-like signal in the nonunion interspace. The adjoining $2-3 \mathrm{~cm}$ of bone marrow proximal and distal to the sternal nonunion show diffuse increased signal alterations (arrows), consistent with active bone reaction. These regions were also clinically painful 

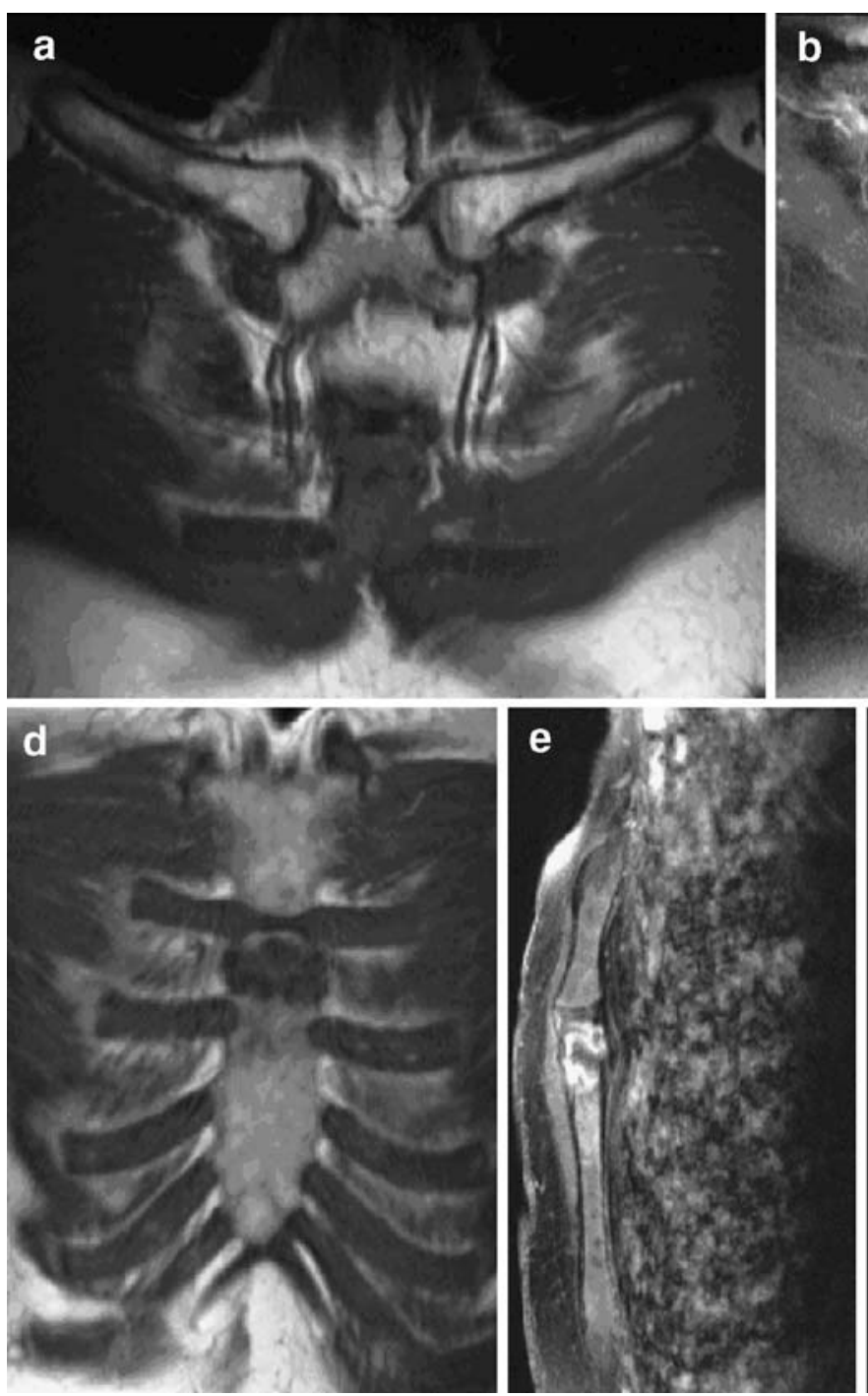

Fig. 2 Sixty-six-year-old medical doctor with sternal nonunion. a-c Initial MRI was obtained 1 month after the chest trauma. a Coronal (TR/TE; 585/17) T1-weighted image shows decreased bone marrow signal intensity adjacent to the sternal fracture. b Coronal (TR/TE; 585/17) and c sagittal (TR/TE; 595/12) T1-weighted fat-saturated MR images after intravenous contrast administration demonstrate increased contrast enhancement within the proximal and distal fragment ends adjacent to the fracture line. There is some soft tissue high signal related to the fracture. d, e Follow-up MRI, was obtained 9 months after the initial trauma. d Coronal (TR/TE; 585/17) T1-weighted

persistent severe pain. Post-traumatic changes in the manubrio-sternal joint were seen in 2 patients. On MRI, there were signal intensity abnormalities in the manubrio-sternal joint, and these findings were directly related to the episode of acute trauma and considered to be due to post-traumatic changes or stress reaction following trauma (Figs. 4, 5).

\section{Discussion}

Prolonged sternal pain after thoracic trauma is a troublesome complication, seriously handicapping patients. The
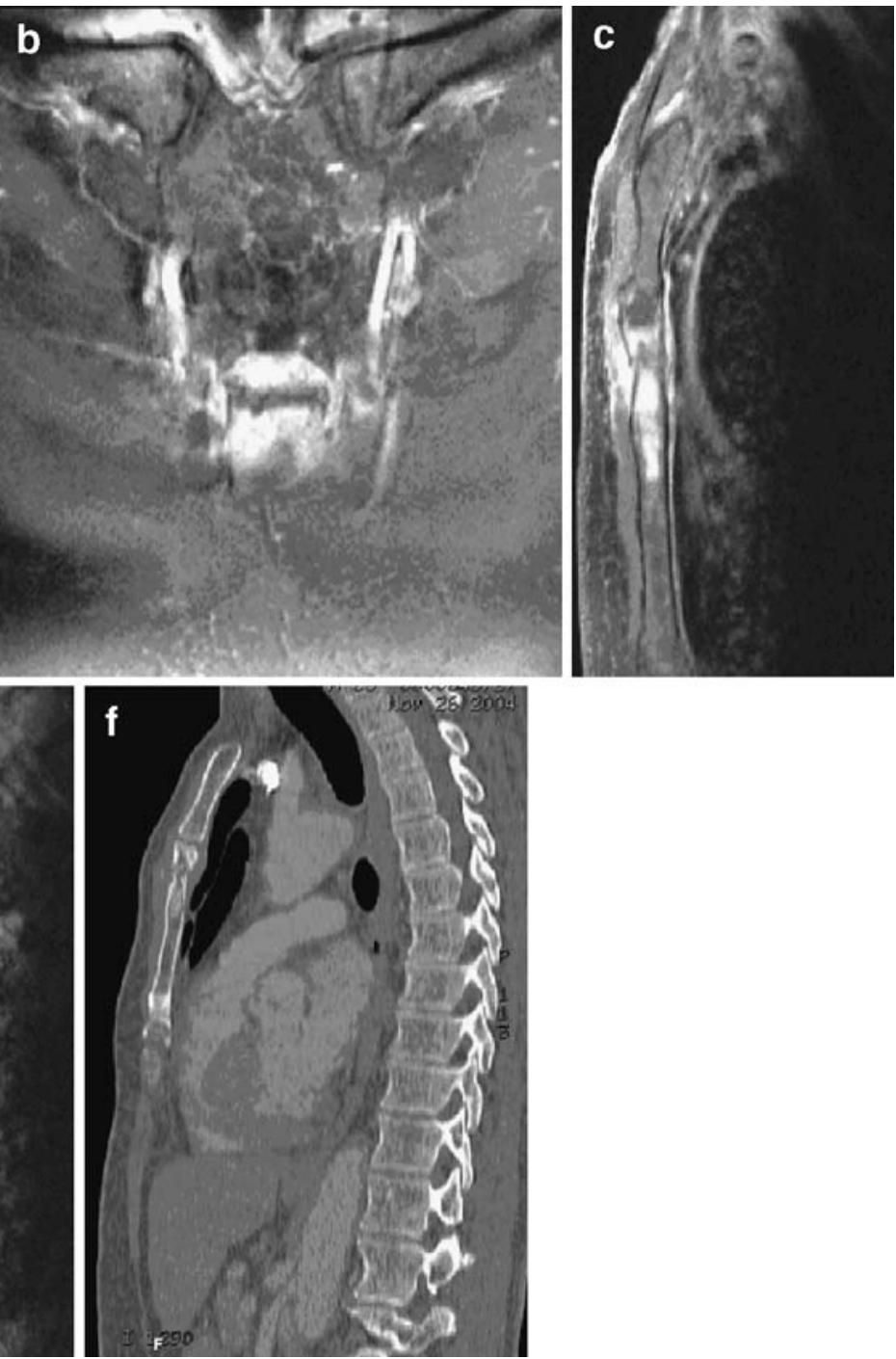

image still demonstrates a focal area with decreased signal intensity of the bone marrow adjacent to the gap. e Sagittal (TR/TE; 595/12) T1weighted fat-saturated image after contrast administration shows enhancement of the bone marrow adjacent to the bony defect in the sternum and low signal intensity within the fracture interspace. Gadolinium outlines the fracture line, demonstrating well-marginated fracture ends and a slight ventro-dorsal off-set. f Sagittal CT reconstruction performed 2 weeks after the MRI shows a sternal disruption and sclerosis of the fracture ends, but provides no further information compared with the MR image

causes of sternal pain following trauma include nonunion or delayed union of sternal fracture and post-traumatic changes of the manubrio-sternal joint [1-6]. Delayed union is a prolongation of time to fracture union [7-11]. Endosteal bone formation is present, but there is a cessation of periosteal response before the fracture has successfully healed [7-11]. Nonunion is the cessation of periosteal and endosteal healing [7-11]. Although some authors define nonunion of the sternum as a persistent fracture of the sternum after 3 months without signs of bone healing [12], and other authors as the cessation of bone healing for more than 6 months in the absence of infection [13], there is 


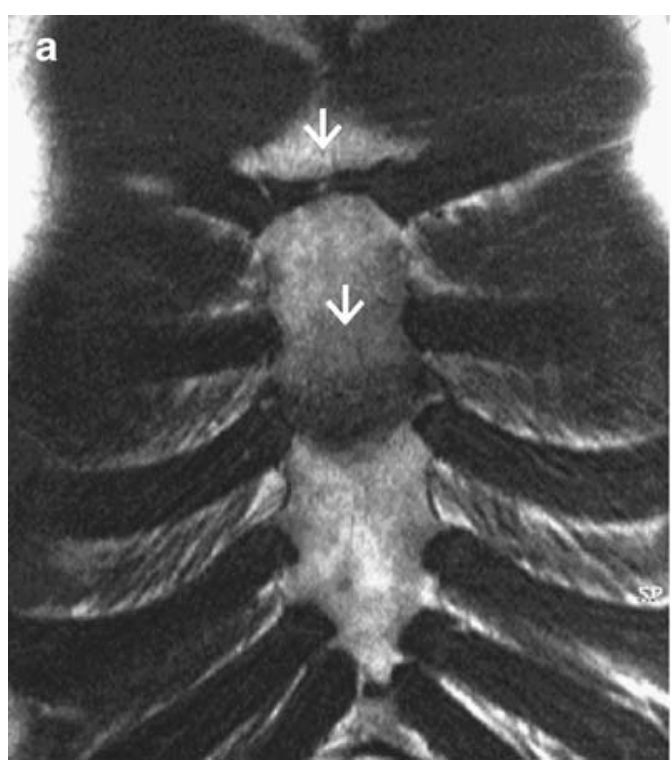

Fig. 3 Fifty-six-year-old policeman after chest trauma. a Coronal T1weighted MR image (TR/TE; 585/12) shows a hypointense transverse line in the mid third of the sternum (lower arrow). b On the corresponding coronal STIR sequence (TR/TE; 4,100/17) this line shows increased signal intensity (lower arrow). c The sagittal STIR sequence (TR/TE; 4,000/38) demonstrates a ventro-dorsal off-set with a minor anterior displacement of the distal sternal part (lower arrow), but with preserved anterior and posterior continuity. The sternal edges adjacent to the focal area seem to be smooth, and the bone marrow adjacent to the area shows normal signal intensity. Intraoperatively, an edematous bone callus was evident, but no sternal nonunion with sternal gap and fluid or granulation tissue. The pain was due to the minor displacement of the proximal and distal sternal portions with subsequent delayed union. Additionally, focal increased signal intensity alterations are seen adjacent to the manubrio-sternal joint on the coronal and sagittal STIR sequences $(\mathbf{b}, \mathbf{c})$, and some fluid is seen in the joint gap (upper arrows)

reported to occur with an incidence of less than $1 \%$ [12] and has been sparsely mentioned in a few reports concentrating primarily on $\mathrm{CT}$ for the evaluation of sternal complications after sternotomy [14-16]. Sternal nonunion following thoracic trauma is encountered even less often given the low incidence of sternal fractures, which account
Fig. 4 Thirty-year-old woman with pain localized to the manubrio-sternal synchondrosis after severe sternal contusion. a Coronal T1-weighted image (TR/ TE; 569/12) shows decreased and b coronal (TR/TE; 4,615/ 76) STIR sequence shows increased signal intensity of the bone marrow adjacent to the manubrio-sternal joint (arrows), indicating bone marrow edema possibly due to prolonged bone contusion as the result of direct trauma or stress response after trauma
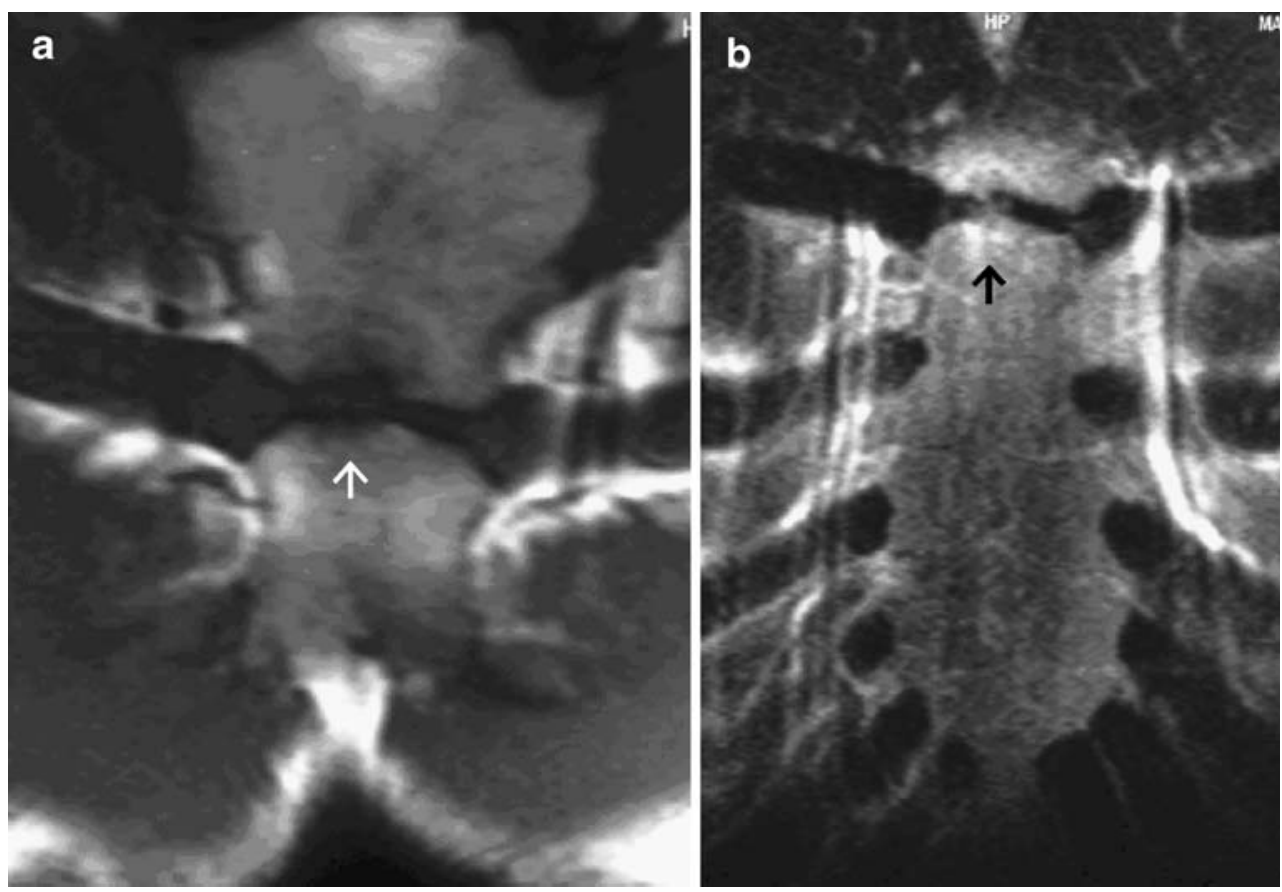
Fig. 5 Fifty-two-year-old parachuter with prolonged chest pain after polytrauma. a Coronal T1weighted MR image (TR/TE; 585/17) shows decreased bone marrow signal intensity adjacent to the manubrio-sternal synchondrosis and within the joint. b Coronal (TR/TE; 4,842/17) and $\mathbf{c}$ sagittal (TR/TE; 3,731/76) STIR sequences demonstrate increased signal intensity of the bone marrow and within the synchondrosis. d Coronal T1weighted fat-saturated (TR/TE; 900/17) MR image after gadolinium administration demonstrates enhancement of the bone marrow adjacent to the manubrio-sternal synchondrosis
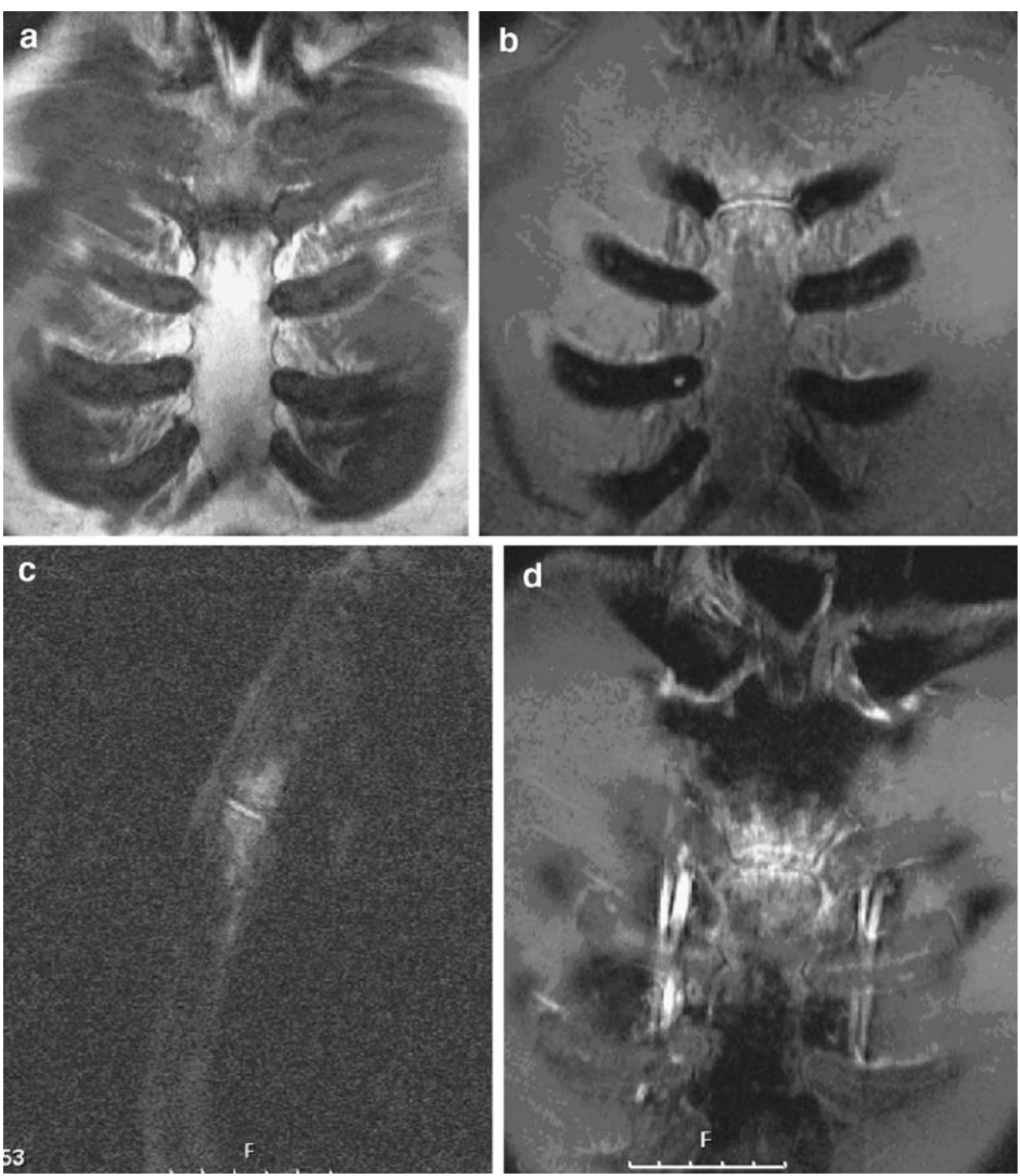

for less than $0.5 \%$ of all fractures [17]. Also, it has to be considered that some patients with sternal nonunion may be asymptomatic. Sternal fractures are particularly uncommon in young adults due to the elasticity of the rib cartilages in this age group [18]. Sternal fractures may be the result of direct trauma to the anterior chest wall by steering wheel, fist blow, etc., hyperextension trauma or flexion-compression injury to the spine. A direct blow to the lower portion of the sternum is the most common mechanism [17].

Due to its rare occurrence post-traumatic sternal nonunion is a rare condition with only a few cases reported in the surgery and orthopedic literature, with emphasis on treatment options, pathogenesis, and clinical presentations $[1,3,4]$. So far, however, there have been no reports and no series in the radiological literature.

The pathogenesis of post-traumatic sternal nonunion is considered to be multifactorial. Risk factors include diabetes mellitus, chronic obstructive pulmonary disease, obesity, steroid medication, fracture dehiscence, and decreased vascularization of the bone fragments and instability $[12,19]$.

We analyzed the MR images of sternal nonunion with (case 2) and without (case 1) intravenous contrast material administration and identified three common MRI features:

1. A disruption of the sternal continuity with a sternal gap or obvious dehiscence

2. Fluid-like signal in the nonunion interspace

3. Signal alterations of the bone marrow adjacent to the sternal gap, indicating bone marrow edema.

Magnetic resonance imaging is known to be a sensitive method of identifying fractures. As shown in our study, it is also helpful for detecting other post-traumatic disorders responsible for prolonged chest pain. Artefacts caused by movement or breathing during data acquisition may be 
restricted by using the prone position. While sternal nonunion was clinically suspected in case 3 , MRI demonstrated a slightly dislocated sternal fracture with a focal zone of low-signal intensity on the T1-weighted images and of high-signal intensity on the STIR sequences between the dislocated fracture ends, completely filling the fracture interspace between the proximal and distal sternal portions, without evidence of edema in the adjoining bone marrow. Surgery performed for sternal revision and refixation revealed the presence of an edematous callus. There was no evidence of sternal nonunion. Sternal nonunion may present with fluid in the nonunion interspace or as a complete fibrous union with granulation tissue. In case 3, however, there was no sternal gap, the anterior and posterior cortical bone was preserved, and the bony edges were smooth. The displacement of the fragment ends suggested delayed bone healing.

Clinically, both disorders, sternal nonunion and delayed union, may present with sternal pain. In our case of delayed union, based on the severe pain, surgery was performed with partial sternal resection and refixation. This treatment option was considered to be adequate in this condition based on the clinical grounds.

In 2 patients (cases 4 and 5) with prolonged sternal pain after sternal trauma we found no evidence of previous sternal fracture or sternal nonunion, but we did find signal intensity changes in the manubrio-sternal joint, which we thought were due to prolonged post-contusional bone edema or stress response after trauma, and which we termed manubrio-sternal synchondrosis. This entity has not as yet been reported in this setting in the radiological literature. Other rare disorders after sternal trauma are manubrio-sternal dislocation [6] or displacement of the clavicle and rib [20].

Computed tomography was acquired in 1 patient with post-traumatic sternal nonunion (case 2). CT is commonly used for diagnosing sternal nonunion [13, 21]. Our cases, however, suggest that MRI can be effectively used for the evaluation of sternal nonunion. MRI depicts bony sternal defects, subtle alterations of the bone marrow signal intensity indicative of bone marrow activity, and fluid collections.

In summary, the major differential diagnoses to be considered in patients with prolonged post-traumatic sternal pain in the absence of infection include post-traumatic sternal nonunion and delayed healing of the sternum following sternal fracture and post-traumatic changes in the manubrio-sternal synchondrosis. MRI can differentiate between these post-traumatic sternal disorders.

\section{References}

1. Hensinger RN, Berkoff HA. Traumatic non-union of the sternum. J Trauma 1975;15(2): 159-162.

2. Mayba II. Sternal injuries. Orthop Rev 1986;15(6): 364-372.

3. Mayba II. Non-union of fractures of the sternum. J Bone Joint Surg Am 1985;67(7): 1091-1093.

4. Coons DA, Pitcher JD, Braxton BT. Sternal nonunion. Orthopedics 2002;25(1): 89-91.

5. Lichtman HM, Silver CM, Simon SD, Tamura H. Post-traumatic degenerative arthrosis in the manubriosternal joint. Clin Orthop Relat Res 1969;67: 111-115.

6. Kalicke T, Frangen TM, Muller EJ, Muhr G, Hopf F. Traumatic manubriosternal dislocation. Arch Orthop Trauma Surg 2006;126 (6): 411-416.

7. Marsh D. Concepts of fracture union, delayed union, and nonunion. Clin Orthop Relat Res 1998;355: 22-30.

8. Bartels KE. Nonunion. Vet Clin North Am Small Anim Pract 1987;17(4): 799-809.

9. DeAngelis MP. Causes of delayed union and nonunion fractures. Vet Clin North Am 1975;5(2): 251-258.

10. Boer FC, Patka P, Bakker FC, Haarman HJ. Current concepts of fracture healing, delayed unions, and nonunions. Osteo Trauma Care 2002;10: 1-7.

11. Einhorn TA. The science of fracture healing. J Orthop Trauma 2005;19(10): 4-6.

12. Wu LC, Renucci JD, Song DH. Sternal nonunion: a review of current treatments and a new method of rigid fixation. Ann Plast Surg 2005;54(1): 55-58.

13. Hendrickson SC, Koger KE, Morea CJ et al. Sternal plating for the treatment of sternal nonunion. Ann Thorac Surg 1996;62: 512-518.

14. Templeton PA, Fishman EK. CT evaluation of poststernotomy complications. AJR Am J Roentgenol 1991;159: 45-50.

15. Li AE, Fishman EK. Evaluation of complications after sternotomy using single- and multidetector $\mathrm{CT}$ with three-dimensional volume rendering. AJR Am J Roentgenol 2003;181: 1065-1070.

16. Bitkover CY, Cederlund K, Aberg B, Vaage JV. Computed tomography of the sternum and mediastinum after median sternotomy. Ann Thorac Surg 1999;68: 858-863.

17. Kurzweg FT, Danna SJ, Lolley RT. Open reduction and fixation of a comminuted fracture of the sternum. J Thorac Cardiovasc Surg 1972;63: 424-426.

18. Gibson LD, Carter R, Hinshaw DB. Surgical significance of sternal fracture. Surg Gynecol Obstet 1962;114: 443-448.

19. Bitkover CY, Gardlund B. Mediastinitis after cardiovascular operations: a case-control study of risk factors. Ann Thorac Surg 1998;65: 36-40.

20. Velutini JA, Tarazona PF. Fracture of the manubrium with posterior displacement of the clavicle and first rib. A case report. Int Orthop 1998;22(4): 269-271.

21. Destouet JM, Gilula LA, Murphy WA, Sagel SS. Computed tomography of the sternoclavicular joints and sternum. Radiology 1981;138(1): 123-128. 